\title{
Political Engagement on the Internet and Technologies of Its Implementation in Modern Russia
}

\section{Sokolov Alexander Vladimirivich}

\author{
Candidate of Political Science, associate professor, Chair of Social and Political Theories at Demidov Yaroslavl State University \\ Email: alex8119@mail.ru
}

\section{Doi:10.5901/mjss.2015.v6n2s2p209}

\begin{abstract}
The article presents data of sociological research of the online political participation of citizens and political actors in modern Russia. The research was focused on the Internet political participation as an important component of citizens' political involvement that has a significant impact on a political process in modern Russia. By the political participation on the Internet, we mean the use of Internet technologies to involve different groups of citizens into policy; to organize interaction of political actors and citizens; to affect the formation and implementation of political decisions, formation and functioning of political institutions, activity of political and public organizations as well as to affect the activity of non-system political movements and actions for radical transformation of the existing political system. The article comprises data of the expert opinion polls conducted by the author in October-November 2012 in 4 subjects of the Russian Federation (the Yaroslavl Region, Vologda Region, Ulyanovsk Region and Novosibirsk Region), with the sample of 30 persons. A mass Internet poll was conducted among the users actively participating in online political campaigns, and other politically engaged Internet users, with the sample of 400 interviewees. In this article, the author presents the data results from 15 regions of Russia. A degree of the main actors' Internet political engagement has been analyzed. The authors have determined the most popular and efficient forms and technologies of the Internet participation. Special attention has been paid to the analysis of forms and mechanisms of political actors' Internet participation during election campaigns.
\end{abstract}

Keywords: Internet, political participation, political online campaign, Internet technology, channels of communication

\section{Internet Opportunities for Political Engagement}

One of the features of the modern Russian society is a transfer of political engagement onto the Internet. Wide spread, convenience, accessibility and efficiency of information exchange are factors for the Internet political engagement. Internet applications provide citizens with the opportunities for their active participation in public processes. For example, online access to the decision making process, online consultations on key issues, online sharing of opinions, viewpoints and disputes, etc. Moreover, mass and available ways of communication between people, communities, parties and other society elements are extremely important for the formation of different coalitions and blocks between associations [2].

At the present stage, in the epoch of globalization and information technologies, a civil society is not just a set of organizations. Thanks to the Internet, political processes and management got a new content providing new actors of civil society- online communities[1].

The necessity to involve many concerned actors into the process of solving socially significant problems determines an important role of the Internet for providing their communication in modern conditions. It should be noted, that an online dialogue between certain parts of the society could hardly have taken place in off line regime. On this basis, Internet communication between groups similar in rhetoric and targets, is logical and actual. A wide use of Internet services and tools for social communication, a growth of their part within the communication suggests that the role of online communications in the system of public relations will be increasing and the trends towards the online unification will be growing.

The Internet has provided environment for different activists' societies and projects existing only in a virtual form (for example, help cards, fund-raising, etc.). They are used, if different means of self-realization is difficult to use (high need for anonymity, low capacity to communicate off line, etc.). With the Internet, new kinds of activity, that would have been impossible before, are possible today ( for example, webcam based election monitoring) [3, p. 24].

Different ways to join this or that community determine the difference in the membership. The backbone is the initiative citizens ready to participate regularly. If this part of the members is constantly enlarged, the movement will be changing and developing. In mass movements, the greatest part of the participants is those ready to help only once or 
during a certain period of time. When involving supporters into the public political campaign, the content of the web site and information resources is principally important, as they are the basement for interaction and communication of actors.

It is evident, that modern communication technologies are affecting all the spheres of social life. Using the Internet for the development of public initiatives is an important feature and a method to increase the efficiency. Online interaction is a factor for many participants to get involved into the discussion and editing of the information provided. The necessity to involve a great number of the concerned actors to solve socially important problems determines an important role of the Internet in providing their communication under the modern circumstances.

Open and free communication is the reason for the Internet to be an indispensable tool for social and political actors. At this level, civil initiatives are being implemented into the virtual space that will have results off line.

The Internet is an accessible means of communication, that provides fast and efficient data transfer within the society. For the organizations based on online principles, this is a key feature of the Internet as a communication tool.

\section{Methodology of the Research}

Our research is focused on the Internet political participation as an important component of citizens' political involvement that has a significant impact on a political process in modern Russia.

By the political participation on the Internet, we mean the use of Internet technologies to involve different groups of citizens into policy; to organize interaction of political actors and citizens; to affect the formation and implementation of political decisions, formation and functioning of political institutions, activity of political and public organizations as well as to affect the activity of non-system political movements and actions for radical transformation of the existing political system.

The article comprises data of the expert opinion polls conducted by the author in October-November 2012 in 4 subjects of the Russian Federation (the Yaroslavl Region, Vologda Region, Ulyanovsk Region and Novosibirsk Region), with the sample of 30 persons (deputies of regional and municipal representative bodies, journalists, leaders of regional branches of political parties and public associations, etc.).

The poll was conducted by a semi-formalized questionnaire. That let us get both qualitative and quantitative assessments of the citizens' political participation on the Internet.

To interpret the obtained qualitative data, in November, 2012- January, 2013, a mass Internet poll was conducted among the users actively participating in online political campaigns, and other politically engaged Internet users, with the sample of 400 interviewees. In this article, the author presents the data results from 15 regions of Russia:

1. Vladimir Region;

2. Volgograd Region;

3. Vologda Region;

4. Krasnodar Krai;

5. Novosibirsk Region;

6. Perm Krai;

7. Primorsky Krai;

8. Pskov Region;

9. Republic of Bashkortostan;

10. Republic of Dagestan;

11. Republic of Tatarstan;

12. Rostov Region;

13. Ulyanovsk Region;

14. Khabarovsk Krai;

15. Yaroslavl Region.

Thanks to this geographical coverage, it is possible to get representative data from all around Russia.

As a result, we got both quantitative data on the Internet spread in the political sphere and their interpretation.

\section{Level of Political Participation on the Internet}

One of the research hypotheses is that the level of online political engagement depends on the off line engagement of political actors, and this means that the peak of political actors' online engagement corresponds to the period of maximum political engagement or official election campaign. We have recorded that political forces actively use the Internet to organize protests, to involve supporters, for communication, etc. The experts have also recorded a 
considerable increase of political engagement for the last three years- in average 4.01 .

It should be noted, that the experts predict an increase of the Internet political engagement in the regions in three years (Diagramm 1). The experts from the Ulyanovsk Region and Yaroslavl Region give the highest rates to the increase of potential. The average rate of the experts from the Vologda Region is 2.8. The experts in the Vologda Region note, that even nowadays the system forces tend to block online protest political engagement. Thus, if it goes like this, protest activity on the Internet will likely to get reduced.

Diagram 1. How do you think, how will the activity of political participation in Internet in your region in 3 years? (from -5 to 5)

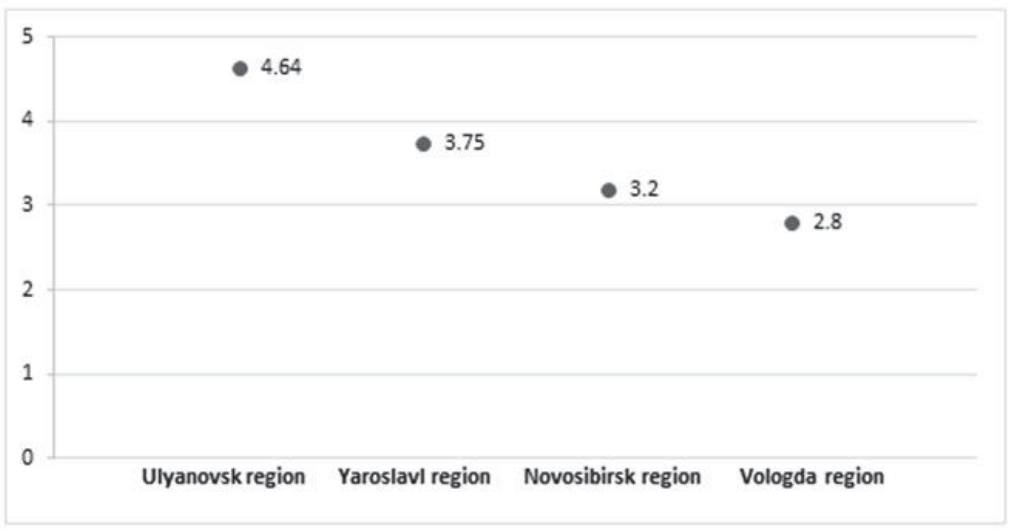

The forecast on the increase of the online political engagement is confirmed by the experts' data on its level nowadays, both during election campaigns and during preparations. The highest rates were not given, that proved the potential for increasing online political participation.

In the conditions of gradual spread of the Internet across the country, citizens involvement into different initiatives and discussions, leaving network for different off line events, we can talk about the increase of civic engagement on the whole. The highest rates of the increase of the online engagement in the regions are recorded in the most politically active regions. Thus, the forecast for the coming future is realistic, provided that strict measures and restrictions against the online political engagement are not applied.

On the whole, among the reasons for different online activity during political campaigns, we can determine objective and subjective ones.

Objective reasons are the level of political culture and activity of the residents of the region. There is a connection between a level of culture and number of political events. The higher the level of political culture and activity of the residents is, the more events and information occasions, including those within the promotion of political projects. Respectively, the use of the Internet for political campaigns is becoming more necessary.

Another objective reason is the difference in the Internet access in different regions. The interviewees note, that in faraway parts of the country the Internet access can be limited or not available, that is why the level of online activity is lower there. Thus, the degree of the Internet use for political campaigns depends on the Internet spread, quality, price and necessity.

One more reason is the level of urbanization in different parts of the country . To the experts' point of view, the citizens' online activity is higher in cities and large settlements.

Subjective factors affecting the quality of the Internet use in political projects, are citizens' activity in politics in this or that region. The higher the activity is, the higher the Internet activity in the politics.

The interviewees understand political engagement, that can have an impact on the Internet, as certain events in social and political life, including unlawful ones.

Another factor is competitive and resonant nature of electoral activity, as during the election campaigns more attention is focused on the politics.

Certain politicians creating information occasions for the Internet, play a considerable role. For example, the Governor of the Kirov Region Nikita Belykh, who promotes the Internet activity in the region.

There is an opinion, that in some regions, the authorities restrict activists' opportunities to speak for their interests and opinions, to take part in public events. These citizens use the Internet for defending their positions as the Internet is free for that. 
We should take into consideration a professional approach to the online political campaigns. That is the work of teams creating the content and working with the public. In case different teams with different level of competitiveness work in different regions, the degree of the Internet use will be different.

It should be noted, that the interviewees still do not have a common opinion whether the Internet activity depends on a region. Some of them doubt that the degree of the Internet use is different in regions. Others distinguish the territories by the boundary 'regions-capital'. There are intermediate views on a gradual reduce of the differences between the regions.

To the experts' point of view, the main reasons for a difference in the use of the Internet in political campaigns in the regions of Russia are the following:

- voter's political culture and activity;

- Internet, proper use of it;

- efficient use of the Internet in political campaigns, that determines the priority of other channels of political information propaganda;

- organizers of discussions, actions, site administrators, specialists and activists;

- $\quad$ political traditions in the region, stereotypes;

- $\quad$ an occasion, reason for the activation.

\section{Internet in the Election Campaigns}

The poll experts were asked to assess the level of the online political participation in an official election campaign ( after the lists of candidates were approved). During the period, according to the experts' assessments, political engagement of system forces is higher than that during a period of preparation for the election campaign, both at all-Russia's level (average rate 6.6 and 5.04 respectively) and regional level.

On the whole, we can say that the experts from all the regions give approximately equal assessment to the online political participation in an official election campaign - 6.6, no considerable deviations (Diagramm 2). This suggests, that the situation with the online political participation is rather holistic, established and ready to be studied. A determined position of the interviewees may be explained by a possible centralization of sources for the online political engagement in Moscow and Saint-Petersburg as the centers of off line policy.

The experts give different assessments to certain regions; thus, the highest rate of the Internet activity is given by the experts from the Yaroslavl Region (7.06), the lowest activity is in the Novosibirsk Region and Vologda Region (approximately 4.8). Taking into consideration the regions location, a geographical principle is not the main one to determine the level of the online political engagement. The Novosibirsk Region and the Vologda Region got similar rates, though the latter is closer to the centre of political engagement. In Russia, this criterion is not a determining one. Probably, the reason is the degree of the Internet spread across the territory of Russia and specific political conditions in each region.

According to the assessment given by experts from the Ulyanovsk and Yaroslavl Regions, these regions can be called one of the most advanced in Russia. Their rates are similar to the overall rate in Russia.

Diagram 2. Expert evaluation of political participation in Internet during the official campaign period (0-10 points, average)

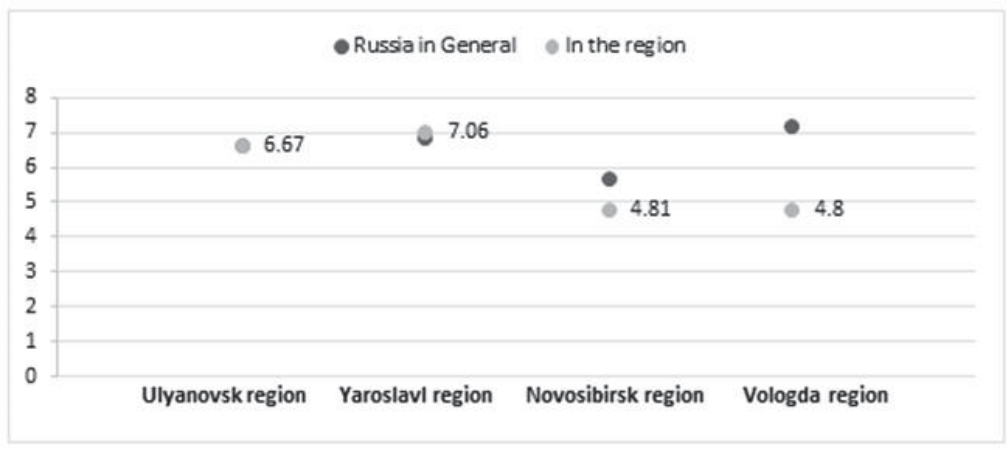

It should be noted, that in the regions in general, the experts give similar assessments to the online political participation in Russia in general during the preparations for election campaigns- 5.4, no considerable deviations. Experts from the 
Vologda Region note a considerable reduce in political engagement before the elections, this rate in the region is lower than that in the country - 3.67 (Diagramm 3).

Diagram 3. Expert evaluation of political participation in Internet in the preparation period of official election campaign (010 points, average)

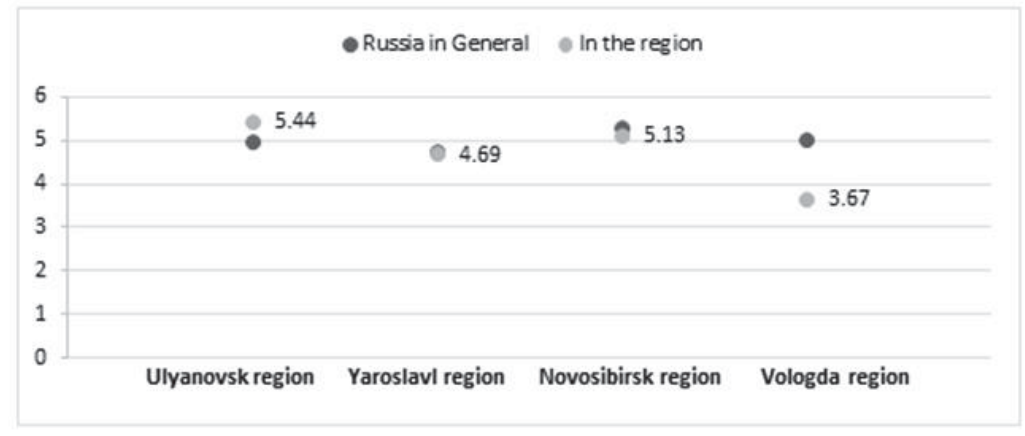

As it was expected, the assessment of the online political participation during the period of preparations for an election campaign is lower than that during the campaign. This suggests that in the assessed regions, except the Novosibirsk Region, Internet users concentrate their political engagement in the period of election campaigns.

These results are rather expected and depend on a variety of factors. The online political engagement is increasing during the period that is interesting for discussing. Apparently, the higher results of the election participation are possible with an active pre-election period, when the population is not very negative towards the politicians, psychological barrier of perceiving information on this topic is reduced. During the period of preparations for an election campaign, the online political engagement must be initiated by candidates to make their activity open and transparent for the citizens, and thus, to involve people into the discussion.

As shown in Diagram 4, the experts do not have a common assessment for the online political engagement of the actors, that do not participate in the elections. At the same time, even in the assessment of the overall situation in Russia, the experts' views differ. The lowest rates of the Internet political engagement in Russia as a whole, were given by experts from the Yaroslavl Region (the region with an overall high Internet activity and where the elections of deputies of the municipality have been just held), the highest rates- in the Vologda and Ulyanovsk Regions. We can conclude, that in these regions, the political forces non-participating in the elections are more efficient on the Internet, than the system forces are. This indicates, that these regions are more receptive to the opposition moods.

Diagram 4. Expert evaluation of political participation in Internet opposition forces, not participating in the elections (0-10 points, average)

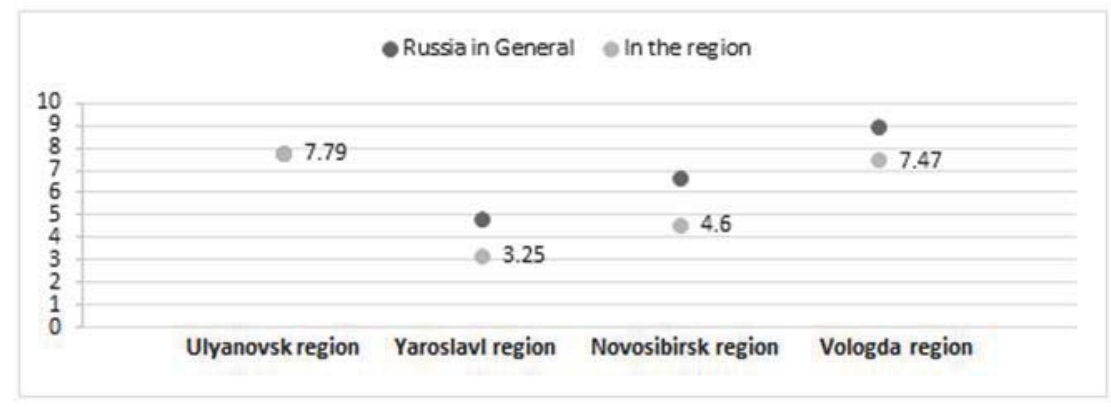

Experts from most of the regions noted that the opposition forces' activity is higher in Russia as a whole than in the region. The exception is the Ulyanovsk Region, where the processes mentioned above were given similar rates.

Apparently, the Internet activity of non-system opposition depends on a geographical factor, as the rates differ in different regions. Nevertheless, the rates in Russia as a whole are higher than regional ones, in three or four regions (The Yaroslavl Region, Novosibirsk Region and Vologda Region). That is why, for the political forces non-participating in the elections, there is a common opportunity to increase their participation on the Internet and to raise it to all-Russia's rate.

To the respondents' opinion, the political forces Internet activity is not zero in a non-election period, but much lower than during the elections. Moreover, the opposition was singled out as the more active party but by a small margin. Each 
of the parties has disadvantages that prevent non-stop activity. Without continued funding, only 'United Russia' party shows episodic activity, opposition parties are practically off line.

Summarizing the experts' opinions, if the political forces' Internet activity is low during a non-election period, the opposition is more active, because with the lack of allocated budget and instructions, the authorities supporters are not engaged. The opposition activity is less noticeable for the lack of resources.

Half of the respondents answered that during municipal or large regional campaigns, the Internet was used by political forces not to a large extent. A quarter of the interviewees think that the Internet is used only for large regional elections. Other experts believe that the Internet is actively used only at one of the two levels presented.

The Internet activists participating in the poll, note a dynamics in the use of the Internet by political forces. But this practice has been just started and is more typical for large election campaigns in cities of the region. At the rural areas elections, this technology is not used as it is not efficient. This trend does not depend on the territory where the campaign is held.

As for the Internet's role in the election campaigns in regions, a general trend is that the low significance of this resource is gradually increasing. In Yaroslavl, a supporting role of the Internet was mentioned, that was a duplication and discussion of the main information occasions of the campaign. Political forces promote their campaigns with the use of the Internet. The Internet is a mechanism to share information.

The respondents enumerated many technologies common for politically active citizens. These are community formation in social networks, dissemination of positive information about the communities and their candidates; anonymous negative information about competitors; compromising evidence and rumors; collecting signatures, etc.

A respondent from Yaroslavl singled out such technologies as 'an observer', 'voters' opinion', 'experts' opinion' and open 'Internet-agitator'.

It should be noted, that the majority of the respondents pointed out the so-called 'dirty' technologies. To their opinion, the Internet has become a platform for concentration of such means of struggle. The key reasons for this are spreading of the Internet and social networks among the electorate, opportunity to send anonymous information. More often, such information comprises rumors, compromising evidence, false news. The information is disseminated at forums, social networks groups. To involve people in such groups, fraudulent schemes are often used. First, such a group or an event with an attractive name is created, and during the election campaign, the name will be changed without the knowledge of subscribers.

We can trace a negative attitude towards the technologies used in the election campaigns. Internet- tools for the public deception are enumerated. For instance, a respondent from the Khabarovsk Krai answered:' Spam, spam, spam, and provocation'.

A respondent from Rostov-on-Don notes that political forces create 'information noise' to suppress real problems and to expose imaginary ones, for example, 'fair elections'. That is done to waste public energy.

Along with some printed editions, the Internet becomes a platform for spreading rumors and black PR technologies during election campaigns. Due to the free access and high speed of disseminating information, this is an important and difficult problem for the political campaign participants.

In most of the regions, however, the experts give a low rate to the Internet use during election campaigns. In the Khabarovsk Krai, Kazan, the reasons are undeveloped communications, low citizens' involvement into political life in general. A respondent from Vladimir answered that such a situation was caused by a lack of public policy in the region. In the Primorsky Krai, Krasnodar, Volgograd, Vologda and the Republic of Dagestan, the respondents state an insignificant role of the Internet in the election campaigns.

In the city of Perm, a respondent rated a significant role of the Internet in Perm-the center of the region, and an insignificant one in districts and towns of the region. In the cities and towns, the most efficient means of communication with the electorate are still personal meetings with candidates. But the experts note an increased role of the Internet in the process both in cities and towns. The same perspective was mentioned by the respondents from Rostov-on-Don and Ulyanovsk.

There are some other factors affecting the intensity of the Internet use in political campaigns in this or that region. One of them is the elections level. The experts have a common opinion, that the higher the level of the elections is, the more significant role the Internet has. Probably, this depends on the funds invested in the campaign. The Internet access and spread in the regions are also of great importance.

\section{Technologies to Organize and Conduct Online Political Campaigns}

As a result, the online political campaign initiators can be divided into two groups: customers and activists. The first group 
includes politicians, the second- engaged participants of the events.

The initiators can be both the organizations implementing their project, and the users who have no other resources but their own activity and the Internet.

The majority of the respondents single out two mechanisms of disseminating information on a political campaign. In the first case, based on his interests, the customer hires professionals and a campaign is initiated. They create a content disseminating in blogs and social networks on the Internet. If the content is supported by target groups, it will be disseminated through the network by reposting, sharing, creating new materials on the base of the content. For example, meme 'Party of crooks and thieves' in 2011.

Very often, successful campaigns are initiated by the people not engaged in the policy. At first, there are just rumors, but because of the resonance, they are transferring into information occasions in the Internet and Mass Media. In this case, professionals use such a good material in someone's interests.

The mechanism for promoting Internet campaigns is becoming similar to off line campaigns. They have similar stages: an idea, plan, organization of the head-quarters and implementation. Another common feature is the criteria of efficiency. These criteria differ in quality, but necessary for the professional approach to the product promotion.

It should be noted, that such thoroughly elaborated campaigns are conducted, more often, by the authorities. As an expert from the Primorsky Krai thinks, the campaigns of opposition have a spontaneous character and are lacking in a worked out plan. Despite this, such campaigns are gathering pace and, on the whole, are more efficient than the others.

A respondent from the Republic of Bashkortostan notes, that a resonant event followed by discussions is important. It helps the groups of like-minded persons find each other, attract and efficiently use the resources. If a project or a campaign are considered by the authorities to be 'undesirable', even with all the resources or teams, administrative measures towards the activists are often fatal.

In Diagram 5, the most popular form of the online political participation typical for all the actors of the political process, is to place applications and appeals in social networks (46.0\%), to discuss and comment on forums and sites (50.8\% of the experts).

Diagram 5. Rate the various forms of political participation on the Internet in terms of the activity of their users

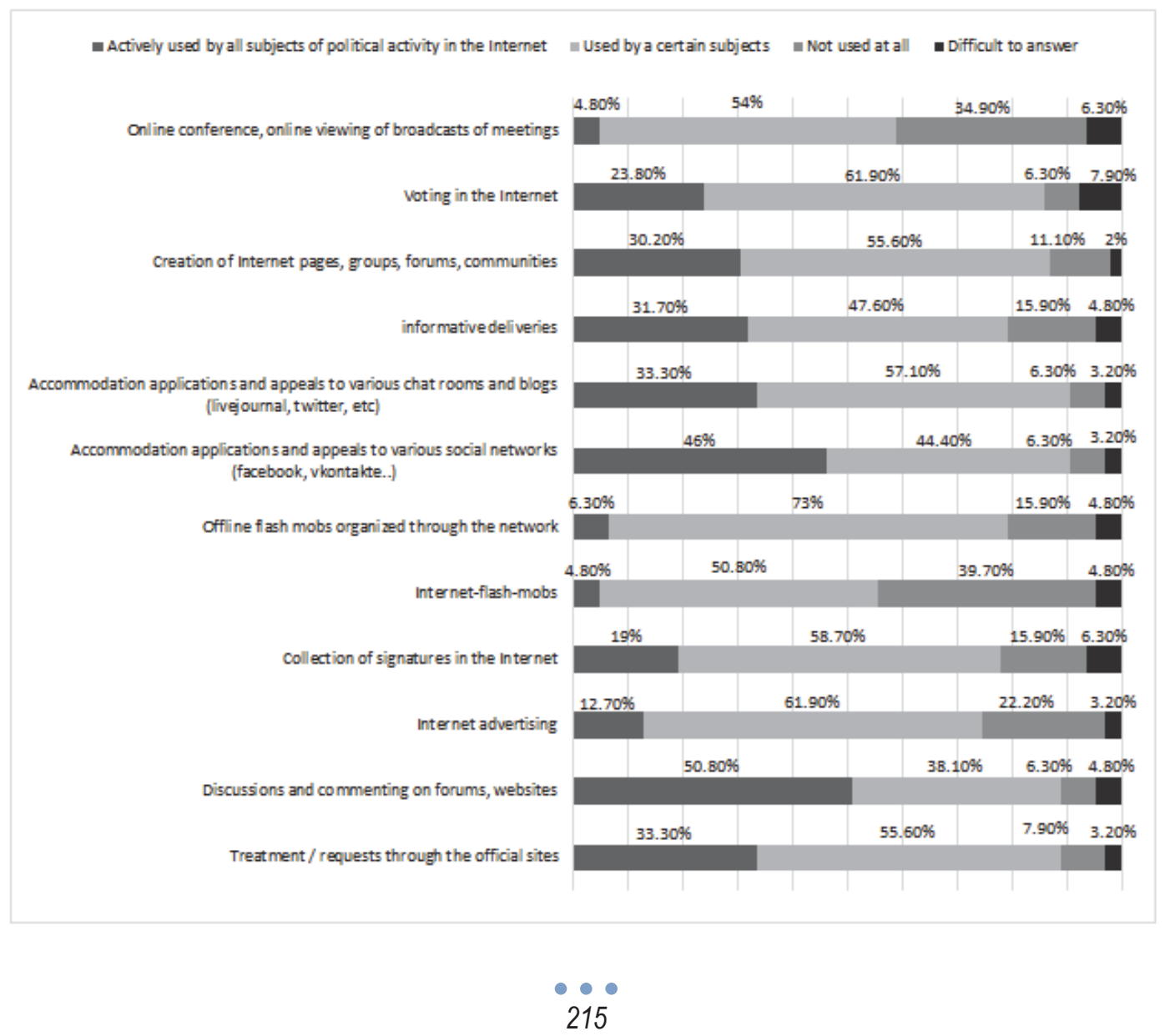


A half of the experts from the Ulyanovsk Region state that political groups hardly ever use Internet advertising (43.8\%) and Internet flash mobs (81.3\%).

Experts from the Yaroslavl Region give a low rate to the use of such technologies as collecting signatures on the Internet (43.8\% of the respondents noted the technology was not used), online conferences, watching sessions online (50 $\%$ of the experts noted the technology was not used).

More than half of the experts from the Vologda Region note, that political groups in the region do not use online broadcast of the conferences and sessions $(60,0 \%)$.

We can conclude, that the tools of political participation are used more often, if they require no great efforts and, particularly, no much time. It is easy to place applications and appeals in social networks, to discuss and comment on forums and sites, and such tools attract the attention of the audience. The events more complicated to implement, for example, online and off line flash mobs, collecting signatures, are used by those who have opportunities and, that is more important, the necessity to use them. Among such users, one should mention the most active participants of social political life, professionals of the online promotion of campaigns, as well as coordinators and other heads of social political projects.

The more frequently used tools are provided by social networks. Due to this and to a great audience, the social networks are the most popular channels of communication of the actors of political engagement. Moreover, they combine the functions of the Mass Media and disseminate information faster than news sites, TV or radio.

It should be noted, that such specific and, to a certain extent, innovative tools as online conferences and Internet advertising, are not in demand of the online wide audience. That means, that to show their political engagement, they would use more common methods which have become the most popular ones according to the poll results.

To place applications, discussions in social networks, blogs, chats is the most popular method of the Internet political participation as it is very convenient, efficient and can partially replace such unpopular forms of activity as Internet advertising, online conferences and sessions. Conference results placed on forums or sites, will be more efficient as the problem, if described briefly, will be read and understood. Participation in online conferences and sessions takes time. Internet advertisements require financial costs.

Thanks to discussions, particularly in social networks, it is possible to organize off line events and flash mobs, to shape public opinion, to disseminate information, etc.

Both of the process parties will get benefit of using social networks as a channel of communication of the political participation. Besides a great number of users of social networks and blogs, they have a convenient form of communication in comparison to some other sites.

As a result, the experts rate social networks as the most popular channel of communication for the Internet political engagement (92.06\%). (Diagram 6) Blogs are in the second place (76.19\% of the experts) and electronic media is in the third place (57.14\%). 38.1\% of the experts pointed out the use of the sites of political parties and public organizations.

Diagram 6. Specify what communication channels most often used for political participation in the Internet?

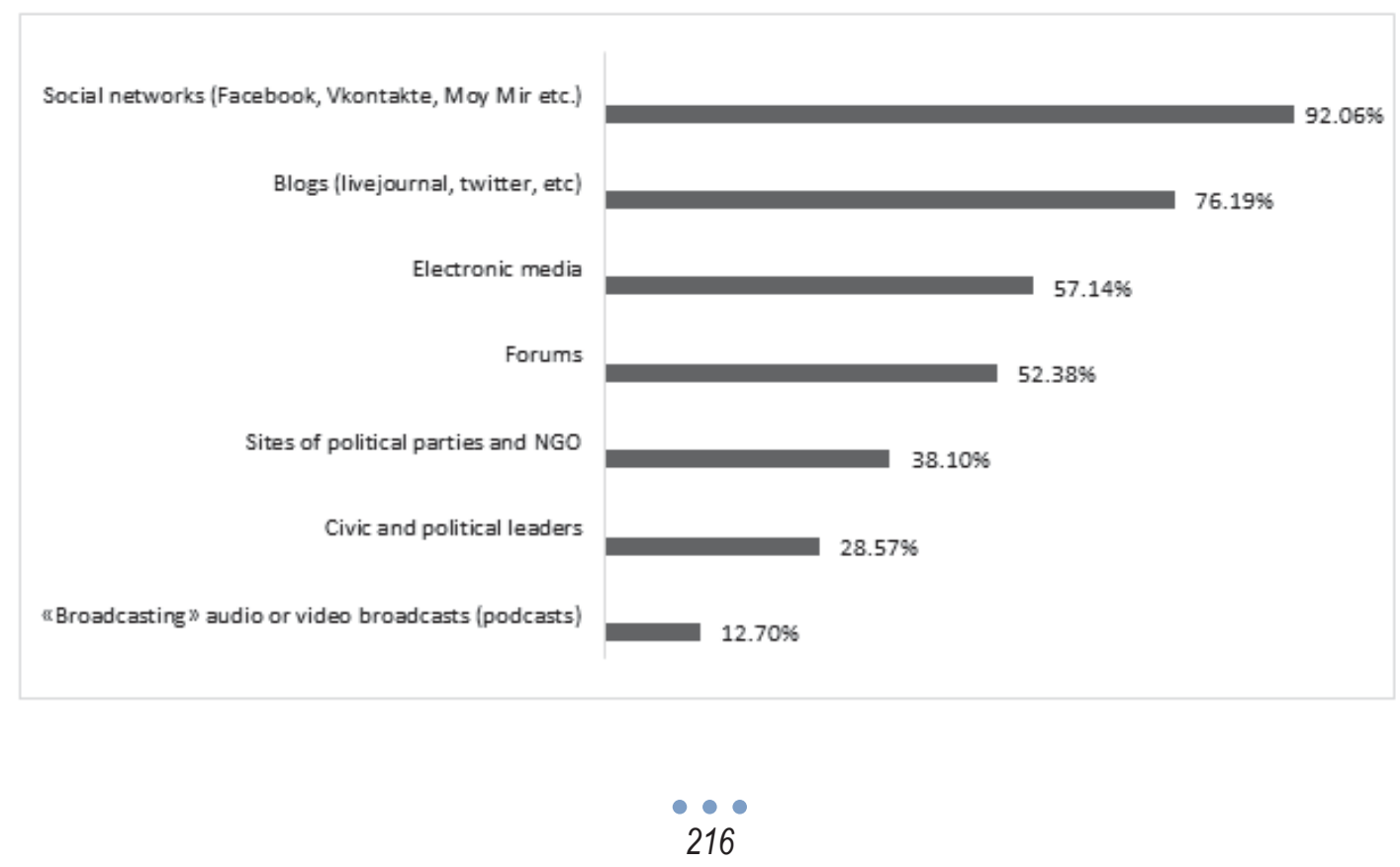


This suggests that the most popular method of the Internet promotion of political projects is social networks. According to the poll results, there are no significant differences in the experts' opinions on this issue in different regions.

The experts determined main Internet tools, frequently used in the political projects:

- means of coordination, organization;

- $\quad$ means of disseminating information, shaping opinion, means of influence;

- means of sharing information.

In general, the list of the Internet-tools is as follows:

- $\quad$ three largest social networks VK, Facebook, Twitter. Additionally, video hosting Youtube.

- electronic media;

- forums;

- sending photos and videos in social networks, implementing rumors, participation in the discussions on different topics;

- blogs posts, microblogging;

- audio and video chats, mailings, torrent distribution inside the organization;

- online conferences, online congresses;

- polls;

- organization of off line political events by means of social networks;

- PR attacks on the authorities.

\section{Conclusions}

One of the main reasons of the increased role of the Internet is that it is turning into a strong electoral resource due to a large audience of politically active citizens. Using the Internet, political actors either get a serious public support or lose citizens' confidence.

The Internet is not just a territory for the existent political forces competing- the Internet is creating new political leaders without traditional Mass Media active participation. Thus, on getting popularity as an Internet blogger, who investigates corruption schemes in large companies with the government participation in the capital, Alexei Navalny has become an important political actor.

The research shows there is a high potential of developing the online political participation, new methods to involve supporters, new methods of political communication and public control.

Internet users show the greatest activity in social networks, which provide great opportunities for communication, information dissemination, search of resources.

An accumulated experience of organizing civic engagement in local and regional campaigns, provided a qualitative leap in the development of political participation in 2011 in mass protests, which were a respond to the suspected falsification of the elections to the State Duma of the sixth convocation. All the main protests were organized using social networks and other Internet channels of communication. They made it possible to involve, according to different estimates, up to 150000 citizens in the protest events.

\section{Acknowlegements}

This article was prepared as part of research funded by a grant from Russian Foundation for Humanities №14-33-01241

\section{References}

Belyantsev A.E., Lymar A.V. (2012) Internet Space as a Factor in Modernization of the Institutions of Civil Society. Bulletin of the Nizhny Novgorod University named after N.I.Lobachevsky. N Novgorod. No 6 (1). 284-288.

Bondarenko S.V. (2003) Social Technologies of "Electronic Democracy" (an attempt to verify the construct). In Political Communication in Post-Soviet Russia: Problems of Formation and Development Paradigm. Materials of Section "Political Communication" Third All-Russian Congress of Political Scientists. April, 28-29, 2003. Moscow.

Russian Non-Political Activism: Sketches to a Portrait of the Hero. Report on the Results of a Study of Activism in Russia (2012) [Online] Available: http://grany-center.org/sites/default/files/files/page/otchet_aktivizm.pdf. 
